\title{
The Efficient Market Hypothesis, Price Multiples, And The German Stock Market
}

Darrol J. Stanley, Pepperdine University, USA

Michael D. Kinsman, Pepperdine University, USA

\begin{abstract}
One of the great exercises of financial research is to examine the efficiency of the stock markets. There are many reasons for this endeavor. One is due to the importance efficiency has on the allocation of capital and the impact on economic activity. Others center on the desire to find an exploitable anomaly for active investment management. This paper sought to do both. The paper explores the German stock market over a five year period ending December 31, 2007. The objective was to examine the value of price multiples in developing portfolios that would not only question the efficient market hypothesis for the market but provide an investment tool to achieve above market risk adjusted returns for an active investment style. The paper explored this by creating portfolios of (1) top ranked (low) price multiples and (2) bottom ranked (high) price multiples. Three multiples were chosen. These were (1) Price to Book (PBK); (2) Price to Current Earnings (PEC), and (3) Price to Normalized Earnings (PER). The hypotheses were that low price multiples would outperform, on a risk adjusted basis, high price multiples, and hedged (long/short) would likewise outperform the market on a risk adjusted basis. Support for either of these hypotheses questions the efficiency of the markets and could provide a pragmatic investment strategy. The results of the study suggest not only that the efficiency of the German stock market can be questioned but that a workable investment strategy involving price multiples could be implemented. The results noted that low price multiples outperformed high price multiples in all cases but not necessarily on a risk adjusted basis. Hedged portfolios likewise outperformed the universe and population. Hedged PBK had an Adjusted Sharpe Ratio of 0.50; the Hedged PEC had an Adjusted Sharpe Ratio of 0.30; and the Hedged PER had an Adjusted Sharpe Ratio of 0.23. These should be compared against an Adjusted Sharpe Ratio for the market of 0 . Finally, an equally-weighted Hedged position of PBK, PEC, and PER had an Adjusted Sharpe Ratio of 0.44.
\end{abstract}

\section{INTRODUCTION}

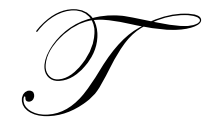

he concept of an efficient market is paramount in investment theory. Eugene Fama (1970) noted that in an efficient market any new information would be immediately and fully reflected in equity prices. Consequently, a financial market quickly, if not instantaneously, discounts all available information. Therefore, in an efficient market, investors should expect an asset price to reflect its true fundamental value at all times. Bruno Solnik (1996) has noted that since the true fundamental value is unknown, the only way to test for market efficiency is to detect whether some specific news is not yet incorporated in the asset price and could therefore be used to make some abnormal profit.

\section{CAPITAL MARKET THEORY}

The variables employed in an attempt to achieve abnormal profits have been numerous. Those variables employed come from one or both subsets of capital market theory. These two subsets of capital market theory are (1) the Capital Asset Pricing Model (CAPM) and (2) the Arbitrage Pricing Theory (APT).

Many researchers prefer the Arbitrage Pricing Theory approach since it requires less stringent assumptions than CAPM and many believe it provides similar results. Richard C. Grinold and Ronald N. Kahn (1995) of 
BARRA noted that "this makes it sound like the APT is a dominant theory. The difficulty is that the APT says it is possible to forecast expected stock returns. But it does not tell you how. It has been called arbitrary pricing theory for just this reason. The CAPM, in contrast, comes with a "user's manual."

This "lack of a user's manual" makes APT a far more complex theory. The APT states that each stock's expected excess return is determined by the stock's factor exposures. The theory doesn't say what the factors are or whether it provides the weighting of the factors. Many, such as Grinold and Kahn, have noted that this is where science steps out and art steps in.

Multi-factor models are in reality three types. Fundamentally, they all must deal with common factors which influence many stocks rather than being specific to a single stock. The three multi-factor models are (1) the Statistical Factor Model; (2) the Macroeconomic Factor Model; and (3) the Firm's Attribute Factor Model.

It is the third multi-factor model, the Firm's Attribute Factor Model, which is of particular interest in this investigation. There are, in general, four subsets. These sub-sets are (1) Economic Factors; (2) Earnings Momentum Factors; (3) Price Momentum Factors; and (4) Valuation Factors.

\section{VALUATION FACTORS}

It is the latter subset, Valuation Factors, which is the focus of this paper on the German Stock Market. Valuation factors have become increasingly popular due to publicity given to Warren Buffett and others engaged in so-called intrinsic valuation investing. Hence, there are multiple models for valuation measurement.

This paper chose to use three valuation measurements. These were (1) Price to Book (PBK); (2) Price to Current Earnings (PEC); and (3) Price to Normalized Earnings (PER). The first two price multiples are well known. The third is actively used as well but not as common. Price to Normalized Earnings can be best noted by taking an eight year regression of time and earnings per share. The regressed or eighth year earnings per share become the "normalized earnings" to apply against the price. This allows for a company currently unprofitable (and not included in any PEC listing) to be included in a study.

\section{VALUATION AND EFFICIENT MARKETS}

Valuation is the most important aspect of active portfolio management. Active managers, in order to justify their roles and compensation, must believe their assessment of value is better than the market or consensus assessment by providing a risk-adjusted return greater than a buy and hold strategy. The modern theory of valuation connects stock values to risk-adjusted expected total returns. This theory of valuation is closely related to the theory of option pricing and is consistent with CAPM and APT. Further, valuation, or perhaps, more importantly misvaluation, is clearly connected to expected returns.

Assume that in any domestic APT model, some form of the firm's attributes will be incorporated. In this context, the domestic APT model proposed by Grinold and Kahn (1994) of BARRA notes the importance of valuation fundamentals in its construction. In general, it is an attempt to measure whether the stock is expensive compared to the current fundamentals.

Valuation anomalies fall into the traditional empirical test of the semi-strong form of the Efficient Market Hypothesis. Some studies suggest stock selection based on fundamental security analysis will not outperform the market due to analysis competition. Other studies suggest pockets of price inefficiency exist and produce statistically significant positive abnormal returns.

The valuation parameter of the price earnings multiple is one example (Basu, Levy and Lermon). The legendary Benjamin Graham's (and his research assistant, Warren Buffett) investment strategy favored low PE, higher-quality companies with more stable future earnings and, therefore, stock prices favorable for positive abnormal returns. A study spanning 1956-1975 by Oppenheimer and Schlarbaum (1981) provided further validation 
to the Graham approach. Other valuation parameters have been the focus of other studies (Fama and French (1992); Chan, Harnao and Lakonishok (1991); and Ferson and Harvey (1991)).

\section{RESEARCH HYPOTHESES}

The foregoing demonstrates there is research to support the predictive capabilities of valuation rules, at least, in the U.S. markets. This avenue of research is now being expanded to analyze the German stock market.

The first hypothesis herein tested is the classical Benjamin Graham thesis against a section of German equities: low valuation outperforms high valuation as well as a buy and hold market strategy (the index). The valuation proxies utilized in the study as previously noted were (1) Price to Book (PBK); price to current earnings (PEC), and (3) price to normalized earnings. If the results are in the predicted direction and high enough on a riskadjusted basis, the German stock market efficiency can be questioned.

The second hypothesis herein tested is that the hedged portfolios (going long the low price multiples and short the high price multiples) of the above valuation proxies will be positive on a risk-adjusted basis. This likewise calls into question the German stock market efficiency but also will allow for investors to achieve a riskless return.

The hypothesis of this paper is that stocks with high price momentum will outperform stocks with low price momentum on a risk-adjusted total return basis. If this be the case, the efficiency of the German stock market could be subject to question.

\section{DATA AND METHODS}

This paper will explore the total return behavior, risk-adjusted, of German equities selected by the above noted hypothesis. The data source is First Call World Equities. The study will involve a five year period ending December 31, 2007. The initial study year contains 1016 stocks decreasing to 853 in the last year. The data is so constructed that the three most common biases are eliminated. There is no look ahead bias, no restatement bias, nor any survivorship bias to the data. Ford Equity Research provided their estimate of normalized earnings. Mergent provided their estimate of the financial strength of the company on a nine point scale 1 (best) to 9 (worse), A-priori, it was decided only to use stocks six or better (B- or better) in the study. This resulted in the size of the population being reduced to about $28.77 \%$ on average.

The stocks will be selected into the top twenty and bottom twenty for a five-year analysis. The stocks will be re-balanced on a yearly basis. All results will be expressed in local currency on a total return basis.

An estimate of turnover and transaction costs will be made in order to allow the use of the methodology in pragmatic investment management. Output variables noted were (1) Capitalization (expressed in millions of local currency); (2) earnings variability (the standard error as a percent of normalized eight year earnings as regressed); (3) current to normalized earnings; (4) the estimated growth rate; (5) dividend yield; (6) quality; and (7) debt to assets.

\section{DATA RESULTS}

A summary of the results of the study can be found on the following pages. 


\section{GERMAN PRICE MULTIPLE STUDY}

SUMMARY 2003-2007

Item $\quad$ PBK $\quad$ PEC PER B-or Better cerman Stock

\section{(I) PORTFOLIO RETURNS AND STATISTICS}

Indexed Top 20 CAGR
Indexed Bottom 20 CAGR
Hedged CAGR
Equally-Weighted Hedged--Avg.
Indexed Top Adj. Sharpe Ratio
Indexed Bottom Adj. Sharpe
Hedged Adj. Sharpe Ratio
Equally-Weighted Hedged ASR

Average Annual Turnover Top

Average Annual Turnover Bottom

Average Universe N(B- or Better)

Average Stock Market N

Average Percentage in Study

\begin{tabular}{|c|c|c|c|c|c|}
\hline $39.76 \%$ & $21.65 \%$ & $33.69 \%$ & $24.12 \%$ & $26.97 \%$ & \\
\hline $23.12 \%$ & $17.01 \%$ & $28.38 \%$ & $24.12 \%$ & $26.97 \%$ & \\
\hline \multirow[t]{2}{*}{$16.63 \%$} & $4.64 \%$ & $5.31 \%$ & $0.00 \%$ & $0.00 \%$ & \\
\hline & & & $0.00 \%$ & $0.00 \%$ & $10.14 \%$ \\
\hline 1.24 & 2.15 & 1.21 & 2.37 & 1.48 & \\
\hline 1.81 & 1.38 & 1.57 & 2.37 & 1.48 & \\
\hline \multirow[t]{2}{*}{0.5} & 0.3 & 0.23 & 0 & 0 & \\
\hline & & & 0 & 0 & 0.44 \\
\hline $47.50 \%$ & $77.50 \%$ & $56.25 \%$ & & & \\
\hline \multirow[t]{3}{*}{$52.50 \%$} & $24.12 \%$ & $26.97 \%$ & & & \\
\hline & & & 244 & & \\
\hline & & & & & $28.77 \%$ \\
\hline
\end{tabular}

(II) TOP 20 PRICE MULTIPLE STATISTICS

$\begin{array}{lrrr}\text { Mean } & 0.704 & 7.207 & 6.205 \\ \text { Median } & 0.745 & 7.202 & 6.3 \\ \text { Mean STD } & 0.275 & 2.662 & 1.985 \\ \text { Minimum } & 0.012 & 0.712 & 1.5 \\ \text { Maximum } & 1.209 & 11.3 & 10.1 \\ \text { N } & 120 & 120 & 120\end{array}$

(III) BOTTOM 20 PRICE MULTIPLE STATISTICS

$\begin{array}{lrrr}\text { Mean } & 15.16 & 247 & 62.29 \\ \text { Median } & 9.914 & 95.35 & 36.4 \\ \text { Mean STD } & 18.17 & 309.5 & 77.5 \\ \text { Minimum } & 5.797 & 50.5 & 3.3 \\ \text { Maximum } & 99.99 & 999.9 & 5152 \\ \text { N } & 120 & 120 & 120 \\ & & & \\ \text { (IV) UNIVERSE PRICE MULTIPLE STATISTICS } & & \\ & & & \\ \text { Mean } & & & \\ \text { Median } & 3.217 & 32.4 & 26.57 \\ \text { Mean STD } & 2.163 & 19.4 & 18.7 \\ \text { Minimum } & 5.179 & 64.58 & 42.01 \\ \text { Maximum } & 0.012 & 0.712 & 1.5 \\ \text { N } & 99.99 & 822.2 & 980 \\ & 1556 & 1339 & 1520\end{array}$




$\begin{array}{lccccc}\text { German } \\ \text { Item } & \text { PBK } & \text { PEC } & \text { Universe } & \text { PER B-or Better Stock Market }\end{array}$

(V) GERMAN STOCK MARKET PRICE MULTIPLE STATISTICS

$\begin{array}{lrrr}\text { Mean } & 2.729 & 39.78 & 24.77 \\ \text { Median } & 1.453 & 18.7 & 14.95 \\ \text { Mean STD } & 6.396 & 80.84 & 44.72 \\ \text { Minimum } & 0 & 0.002 & 0.4 \\ \text { Maximum } & 99.99 & 822.2 & 999.9 \\ \text { N } & 4931 & 3081 & 4832\end{array}$

\section{(VI) OTHER TOP 20 DESCRIPTIVE STATISTICS}

\section{Capitalization}

Mean

Median

Mean STD

Minimum

Maximum

$\mathrm{N}$

Earnings Variabilty

Mean

Median

Mean STD

Minimum

Maximum

$\mathrm{N}$

Current to Normal Earnings

Mean

Median

Mean STD

Minimum

Maximum

$\mathrm{N}$

Estimated Growth

1674

6144

1
58284

114

170.6

50.5

281.2

1
99

114

$-0.13$

0.895

5.86

$-15.8$

39.65

114

82.91

29.5

184.7

1

999

118

2.813

1.315

8.046

0.51

66.86

118

$-0.76$

0.36

3.573

$-15$

2.08

119

$\begin{array}{rr}8.044 & 10.92 \\ 8 & 10 \\ 5.868 & 5.17 \\ 0 & 0 \\ 24 & 22 \\ 114 & 118\end{array}$

3904

541

10015

1

99118

1507

85.67

31

175.9

1

999

1507

0.864

1

4.296

$-22.7$

82.75

1507
1275

42

5890

0

99118

4800

349.5

154

378.3

1

999

4800

$-6.69$

0.6

43.1

$-984$

222

4800
Mean

Median

Mean STD

Minimum

Maximum

$\mathrm{N}$

7.647
8
4.779
0
25
119

10.22

10

5.694

0

25

1507 


\section{Item
Dividend Yield}

Mean
Mean
Mean STD
Minimum
Maximum
N

$$
3.646
$$

2.7

5.029

0

37.3

114

$\begin{array}{rr}4.425 & 3.409 \\ 3.3 & 2.2 \\ 5.501 & 5.667 \\ 0 & 0 \\ 39.4 & 37.3 \\ 118 & 119\end{array}$

2.399

2
2.825

0

39.4

1507

Quality

Mean
Median
Mean STD
Minimum
Maximum
N

Debt to Assets

0.5076
0.54
0.2276
0.04
0.98

0.5927

0.63

0.2163

0.07

0.97

117
5.361

4.967

7.256

1.795

1.088

1

1507

0.586

0.61

0.234

0

1531

4800

$\begin{array}{rrr}0.5757 & 0.586 & 0.5612 \\ 0.54 & 0.61 & 0.6 \\ 0.2413 & 0.234 & 0.2652 \\ 0.07 & 0 & 0 \\ 0.98 & 1 & 1 \\ 117 & 1531 & 4797\end{array}$

German

Stock Market
1.57

3.788

0
877

4800

(VII) OTHER BOTTOM 20 DESCRPTIVE STATISTICS

Capitalization

\section{Mean \\ Median \\ Mean STD \\ Minimum \\ Maximum \\ $\mathrm{N}$}

Earnings Variablity

$\begin{array}{rr}3639 & 2852 \\ 872 & 533.5 \\ 8880 & 8739 \\ 47 & 25 \\ 47584 & 69806 \\ 107 & 116\end{array}$

2555

587

6509

16

117

$\begin{array}{rr}89.91 & 98.77 \\ 37 & 41.5 \\ 190 & 184.5 \\ 2 & 2 \\ 999 & 999 \\ 107 & 116\end{array}$

208.5
61
313.4
4
999
117

3504

541

10015

1
99118

1507
1275

42

5890

0

99118

4800
Mean
Median
Mean STD
Minimum
Maximum
$\mathrm{N}$
85.67
31
175.9
1
999
1507

4800 


\section{Item
Current to Normal Earnings}

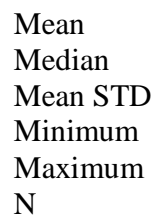

Estimated Growth

$\begin{array}{rrrrr}0.754 & 0.528 & 4.12 & 0.864 & -6.69 \\ 1 & 0.3 & 1.01 & 1 & 0.6 \\ 1.313 & 0.546 & 13.59 & 4.296 & 43.1 \\ -7.7 & 0 & -19.2 & -22.7 & -984 \\ 5.49 & 3.39 & 82.75 & 82.75 & 222 \\ 107 & 116 & 117 & 1507 & 4800\end{array}$

Mean

Median

Mean STD

Minimum

Maximum

$\mathrm{N}$

$\begin{array}{rrrrr}11.98 & 10.67 & 13.5 & 10.22 & 9.49 \\ 11 & 10 & 12 & 10 & 9 \\ 6.965 & 7.33 & 7.39 & 5.694 & 8.722 \\ 0 & 0 & 0 & 0 & 0 \\ 25 & 25 & 25 & 25 & 25 \\ 107 & 116 & 117 & 1507 & 4800\end{array}$

\section{Dividend Yield}

Mean
Median
Mean STD
Minimum
Maximum
N

Quality

Mean
Median
Mean STD
Minimum
Maximum
$\mathrm{N}$

Debt to Assets

$\begin{array}{rrrrr}1.593 & 1.65 & 1.213 & 2.399 & 1.57 \\ 1 & 0.95 & 0.5 & 2 & 0 \\ 1.591 & 3.185 & 2.108 & 2.825 & 3.788 \\ 0 & 0 & 0 & 0 & 0 \\ 6.2 & 25.8 & 19.8 & 39.4 & 877 \\ 107 & 116 & 117 & 1507 & 4800\end{array}$

$\begin{array}{rrrrr}4.925 & 5.259 & 5.308 & 4.967 & 7.256 \\ 5 & 5 & 6 & 5 & 8 \\ 1.139 & 0.835 & 0.876 & 1.088 & 1.795 \\ 1 & 2 & 2 & 1 & 1 \\ 6 & 6 & 6 & 6 & 9 \\ 107 & 116 & 117 & 1507 & 4800\end{array}$

$\begin{array}{rrrrr}0.5912 & 0.6087 & 0.5449 & 0.586 & 0.5612 \\ 0.61 & 0.63 & 0.57 & 0.61 & 0.6 \\ 0.2499 & 0.2755 & 0.2529 & 0.234 & 0.2652 \\ 0 & 0 & 0 & 0 & 0 \\ 1 & 1 & 1 & 1 & 1 \\ 115 & 115 & 116 & 1531 & 4797\end{array}$




\section{(VIII) HEDGED STATISTICS}

\begin{tabular}{lrr} 
& & (A) PBK H \\
Year & \multicolumn{1}{c}{ Top 20 } \\
& 2003 & 45.685 \\
& 2004 & 12.95 \\
& 2005 & 99.834 \\
& 2006 & 37.266 \\
& 2007 & 18.142 \\
& \\
\multicolumn{2}{c}{ PBK Hedged } \\
& \\
\hline \multicolumn{2}{c}{} \\
Mean & 19.0606 \\
Standard Error & 16.91434 \\
Median & 9.382 \\
Mode & \#N/A \\
Standard Deviation & 37.8216 \\
Sample Variance & 1430.474 \\
Kurtosis & -1.25351 \\
Skewness & 0.597223 \\
Range & 92.296 \\
Minimum & -20.456 \\
Maximum & 71.84 \\
Sum & 95.303 \\
Count & 5 \\
\hline
\end{tabular}

(C) PER Hedged

\begin{tabular}{lrr} 
Year & \multicolumn{1}{c}{ Top 20 } \\
& 2003 & 52.706 \\
& 2004 & 17.173 \\
& 2005 & 78.95 \\
2006 & 29.525 \\
2007 & 2.986 \\
\hline \multicolumn{2}{c}{ PER Hedged } \\
\hline Mean & 6.9156 \\
Standard Error & 13.69025 \\
Median & -0.374 \\
Mode & \#N/A \\
Standard Deviation & 30.61233 \\
Sample Variance & 937.1148 \\
Kurtosis & -1.23286 \\
Skewness & 0.195565 \\
Range & 77.321 \\
Minimum & -30.836 \\
Maximum & 46.485 \\
Sum & 34.578 \\
Count & 5 \\
\hline
\end{tabular}

(B) PEC Hedged

$\begin{array}{rrr}\text { Top 20 } & \text { Bottom 20 } & \text { Combined } \\ 28.2 & 12.48 & 15.72 \\ 7.317 & 10.986 & -3.669 \\ 33.652 & 27.655 & 5.997 \\ 16.891 & 33.525 & -16.634 \\ 23.939 & 3.053 & 20.876\end{array}$

\section{German}

Year

$\begin{array}{rrc} & \text { B-Better } & \text { Stock Market } \\ 2003 & 32.32 & 52.151 \\ 2004 & 16.253 & 18.072 \\ 2005 & 35.377 & 43.902 \\ 2006 & 26.964 & 18.553 \\ 2007 & 11.4 & 7.681\end{array}$

$\begin{array}{lrr}\text { Mean } & 24.2628 & 28.0718 \\ \text { Median } & 25.954 & 18.553 \\ \text { Mean STD } & 10.2585 & 18.9525 \\ \text { Minimum } & 11.4 & 7.681 \\ \text { Maximum } & 35.377 & 52.151 \\ \mathrm{~N} & 5 & 5\end{array}$

(D) Equally-Weighted Hedged

$$
\begin{array}{r}
\text { Combined } \\
46.485 \\
-0.374 \\
28.218 \\
-8.915 \\
-30.836
\end{array}
$$

Combined

\begin{tabular}{lc}
\hline \multicolumn{2}{c}{ PEC Hedged } \\
\hline Mean & 4.458 \\
Standard Error & 6.744155 \\
Median & 5.997 \\
Mode & \#N/A \\
Standard Deviation & 15.08039 \\
Sample Variance & 227.4181 \\
Kurtosis & -0.96623 \\
Skewness & -0.49357 \\
Range & 37.51 \\
Minimum & -16.634 \\
Maximum & 20.876 \\
Sum & 22.29 \\
Count & 5 \\
\hline
\end{tabular}

34.906
-4.006
35.352
-5.369
-10.139

\begin{tabular}{lc}
\hline \multicolumn{2}{c}{ Hedged EQ.-WTD. } \\
\hline Mean & 10.1488 \\
Standard Error & 10.24909 \\
Median & -4.006 \\
Mode & \#N/A \\
Standard Deviation & 22.91765 \\
Sample Variance & 525.2189 \\
Kurtosis & -3.25706 \\
Skewness & 0.562863 \\
Range & 45.491 \\
Minimum & -10.139 \\
Maximum & 35.352 \\
Sum & 50.744 \\
Count & 5 \\
\hline
\end{tabular}

\section{DATA ANALYSIS}

An analysis of the data was favorable to the hypotheses. Each of the price multiple subsets presented the following conclusions. 
(1) Price to Book. The low price to book portfolio outperformed the high price to book portfolio at $39.76 \%$ compared to the high price to book portfolio at $23.12 \%$ a difference of $16.63 \%$. The low price to book portfolio outperformed both the universe (B- or better) at $24.12 \%$ and the population at $26.97 \%$. The low price to book portfolio did not, however, outperform on a risk adjusted basis. The Adjusted Sharpe Ratio (Mean/Standard Deviation) stood at 1.24 compared to 2.37 for the universe and 1.48 for the population. Turnover averaged $47.50 \%$

(2) Price to Current Earnings. The low price to current earnings portfolio outperformed the high price to current earnings portfolio at $21.65 \%$ compared to $17.01 \%$. The portfolio did not outperform either the universe or the population. On an Adjusted Sharpe Ratio it did produced a score at 2.15 compared to 2.37 for the universe and 1.48 for the population. Turnover averaged $77.50 \%$.

(3) Price to Normalized Earnings. The low price to normalized earnings outperformed the high price to normalized earnings at $33.69 \%$ compared to $28.38 \%$. This $33.69 \%$ outperformed both the universe at $24.12 \%$ and the population at $26.97 \%$. The Adjusted Sharpe Ratio at 1.21 was inferior to the universe at 2.27 and the population at 1.48 . Turnover averaged $56.25 \%$.

(4) Hedged Price to Book. The hedged portfolio (going long the low 20 stocks and shorting the high 20 stocks) resulted in a favorable Adjusted Sharpe Ratio of 0.5 with an mean return of $19.06 \%$. This compares to an Adjusted Sharpe Ratio of 0 for both the universe and population. Turnover averaged $47.50 \%$ for the long and $52.50 \%$ for the short.

(5) Hedged Price to Current Earnings. The hedged portfolio resulted in a favorable Adjusted Sharpe Ratio of 0.30 compared to 0 for both the universe and the population. Turnover for the long averaged $77.50 \%$ and $24.12 \%$ for the short.

(6) Hedged Price to Normalized Earnings. The hedged portfolio had an Adjusted Sharpe Ratio of 0.23 with a mean return of $6.9156 \%$. Turnover for the long stood at $56.25 \%$ while the short stood at $26.97 \%$.

(7) Hedged Equally-Weighted. The hedged equally-weighted portfolio takes into account all three of the hedged portfolios. It showed a clear advantage with an Adjusted Sharpe Ratio of 0.44 and a risk-free return averaging $10.14 \%$, Transaction costs would be substantial as six portfolios (noted above) are utilized.

\section{CONCLUSIONS}

The results of this study are in line with others clearly indicating the superior performance of low price multiple investing for wealth maximization. Two of the three (PBK and PER) provided superior returns to both the universe and population. It is quite possible that the PBK strategy (with a return of 39.76\% some $12.79 \%$ better than the population) could outperform after transaction costs (commissions, bid-ask spreads, and slippage). Unfortunately, neither of them had superior Adjusted Sharpe Ratios. All three of the low price multiples outperformed high price multiples (PBK, PEC and PER) not only in terms of returns but Adjusted Sharpe Ratios as well. In an efficient market, this should not occur.

The hedged portfolios likewise clearly dominated both the universe and the population. While not overly pragmatic for investment management due to transaction costs (except price to book), they clearly show the inefficiency of the German stock market.

The Efficient Market Hypothesis remains one of the cornerstones of investment theory. The fact that low price multiple strategies continue to achieve superior performance however remains a paradox. It is well known and should therefore not exist either in the United States or as demonstrated by this paper in Germany. Both are developed markets with signal informational knowledge. This observable inefficiency should not exist.

\section{REFERENCES}

1. Basu, Sanjoy. "Investment Performance of Common Stocks in Relation to Their Price-Earnings Ratio: A Test of the Efficient Market Hypothesis." Journal of Finance, June, 1977, pp. 663-687.

2. Chan, Louis and Hamao, Yasushi and Lakonishok. "Fundamentals of Stock Returns." Journal of Finance, 1991. 
3. Fama, Eugene and Kenneth French. "The Cross Section of Expected Stock Returns." Journal of Finance, June 1992, pp. 427-465.

4. Grinold, Richard and Ronald R. Kane. Active Portfolio Management. Chicago: Probus Publishing Company, 1995.

5. Solnick, Bruno. International Investments, $3^{\text {rd }}$ Edition, Reading, MA. Addisson-Wesley Publishing Company, 1996.

\section{NOTES}

